\title{
O poder das palavras: descrever e prescrever
}

Ana Claudia Mielki

\section{Resumo:}

Resenha do livro A economia das trocas linguísticas.

\section{Palavras Chave:}

Pierre Bourdieu, trocas linguísticas, cultura.

Abstract:
Book review A economia das trocas linguísticas.

\section{Keywords:}

Pierre Bourdieu, linguistical exchanges, culture.

\section{BOURDIEU, Pierre. A economia das trocas linguísticas. São Paulo: Edusp, 2008, 192pp.}

Desvelar o poder distintivo das palavras, e compreendê-las dentro de uma perspectiva da análise de uma conjuntura social repleta de tensões, este parece ser o objetivo principal da obra de Pierre Bourdieu, $A$ economia das trocas linguísticas (Ce que parler veut dire, título original em francês), lançada em 2008 pela Edusp. A ideia de que "toda ação é uma conjuntura" busca empreender uma crítica a uma análise linguística que busca na singularidade da própria língua, no seu funcionamento interno, as explicações para os diferentes posicionamentos de emissores e receptores num dado momento de fala.

O livro é composto por nove textos agrupados em três partes: a primeira, na qual se estabelece a produção linguística sempre a partir do funcionamento de um mercado lingüístico; a segunda, cujo objeto principal é a constituição do poder simbólico instituído a partir da linguagem - ou das operações de nomeação; e a terceira, na qual são analisados três discursos (Ser e tempo, de Martin Heidegger; Algumas observações críticas a respeito de "Ler O Capital", de Étienne Balibar; e $O$ espírito das leis, de Charles de Montesquieu).

Bourdieu parte de uma crítica às postulações de Saussure, cujo interesse em estudar a língua a partir de sua estrutura interna gerou, segundo o autor, uma autonomização desta em relação a suas condições sociais de produção, reprodução e circulação. Para Bourdieu, "aceitar o modelo saussuriano e seus pressupostos é o mesmo que tratar o mundo social como um universo de trocas simbólicas e reduzir a ação a um ato de comunicação (...). Embora seja legítimo tratar as relações sociais como interações simbólicas, isto é, como relações de comunicação que implicam o conhecimento e o reconhecimento, não se deve esquecer que as trocas linguísticas - relações de comunicação por excelência - são também relações de poder simbólico (...)" (BOURDIEU, 2008: 23-24).

É nessa perspectiva que o autor busca discutir inúmeros aspectos da língua para mapear aquilo que vai 
chamar de mercado linguístico, que funcionaria a partir do encontro de séries causais independentes, como a disposição socialmente modelada por um habitus linguístico e a estrutura de um mercado linguístico, com hierarquias de valor. Tanto o conceito de habitus, desenvolvido por ele ao longo de sua jornada científica, quanto o conceito de distinção, aparecem aqui de forma articulada a um mercado linguístico em pleno funcionamento.

Alvo de suas críticas também são os linguistas "seguidores do pensamento" do filósofo da linguagem John L. Austin. Para Bourdieu, não existe uma força imanente da linguagem. Segundo o autor, o que tais linguistas fizeram foi encontrar na instabilidade da definição de enunciado perfomartivo explícito o pretexto para fazer desaparecer a própria problemática suscitada por Austin acerca da autoridade (Jürgen Habermas teria caído na mesma armadilha). Em outras palavras, a autoridade como aquilo que permite ao locutor (autorizado) dizer aquilo cuja instituição (social) lhe autorizou dizer.

É o que Bourdieu vai mostrar a partir do discurso de Heidegger, ao analisar suas estratégias de eufemização (no sentido freudiano) de utilizar uma característica essencial da linguagem, a saber, o primado da forma sobre o conteúdo, para ocultar elementos recalcados, o que coloca sua obra fora de alcance a partir de um "verbalismo peremptório" que corresponde ao discurso de autoridade do filósofo. Algo próximo é vislumbrado no texto de Balibar quando esse se coloca na posição do sacerdote, aquele que está autorizado (pela instituição "o marxismo") a falar sobre o "profeta de origem".

Ainda que concorde com Austin quando esse afirma que as enunciações servem para "executar uma ação", para Bourdieu, a autoridade de que se reveste a palavra - sua força ilocucionária - vem de uma força que é externa à estrutura da linguagem. É essa autoridade (do locutor e da instituição que o autoriza) somada às propriedades propriamente linguísticas do discurso que permitem a eficácia simbólica da linguagem, operando assim a magia social de pregnância do discurso.

Bourdieu fundamenta sua argumentação primeiramente desconstruindo a ideia de uma língua legítima dada como natural e comumente usufruída por um grupo de sujeitos falantes. Segundo ele, a visão saussuriana de que " "não é o espaço que define a língua, mas a língua que define seu espaço' (...) oculta o processo propriamente político" (Idem, Ibidem: 31) que leva o grupo de falantes a aceitarem tal língua como sendo a oficial.

A língua oficial é apenas tornada legítima em consonância com as condições socioeconômicas que permitem tal legitimação - apenas em virtude de um mercado linguístico. A ideia de uma língua legitimamente oficial é concebida, portanto, num paralelo traçado com o surgimento dos Estados-nação e a necessidade de se definir uma língua padrão.

Se a língua legítima não é um dado natural, sua manutenção envolve um trabalho permanente de correção e distinção, garantido por aqueles cuja função é retraduzir distinções sociais na lógica propriamente simbólica. O sistema escolar teria, assim, cumprido a função determinante de normatizar a língua, de "fabricar semelhanças das quais resulta a comunidade de consciência que é o cimento da nação", conforme explica Bourdieu (2008: 35) a partir das considerações de Georges Davy. Há, portanto, uma intenção política que determina o surgimento das línguas nacionais, a própria constituição (unificação) pelo Estado.

Interessante que o próprio Bourdieu acrescenta, a esse respeito, que é preciso evitar imputar ao processo de unificação toda a responsabilidade pela constituição de uma língua padrão. Isso porque, para ele, a dominação simbólica depende daqueles que sofrem seu impacto, ou seja, dos dominados, que aderem por cumplicidade - e não por submissão passiva a uma coerção externa - ao estatuto legitimado da língua 
oficial. É nessa perspectiva que Bourdieu estabelece um importante enlace com as teorias do discurso.

Primeiro, numa apropriação positiva da obra de Mikhail Bakhtin. É de Bakhtin que Bourdieu traz a ideia de que as palavras não são neutras, estando seu sentido sempre passível de ser modificado segundo a lógica do confronto social pelo sentido. A diferença é que Bourdieu vai tratar essa possibilidade aberta de sentido - o valor - a partir de uma dinâmica de mercado segundo a qual os signos linguísticos estariam sempre dispostos a receber um preço.

Ao falar da antecipação dos lucros como um movimento de antecipação das sanções do mercado que contribui para determinar a própria produção do discurso, numa espécie de autocensura, estabelece um ponto de contato com o conceito de gênero desenvolvido por Bakhtin, segundo o qual "cada campo de utilização da língua elabora seus tipos relativamente estáveis de enunciados", constituídos de três elementos: "o conteúdo formal, o estilo, a construção composicional” (BAKHTIN, 2003: 262).

O mesmo pode ser dito sobre o conceito de estilo - como uma marca formal integrante do gênero - e que, como tal, não é subjetivo, pois só é percebido na relação entre sujeitos no discurso, diante de uma competência de sujeitos perceptores. Em outras palavras, a antecipação dos lucros nada tem a ver com um cálculo consciente, é antes resultado de um habitus linguístico - e de uma tensão do mercado que não é definida abstratamente para qualquer locutor mas, de acordo com Bourdieu, na relação social entre os interlocutores.

Segundo, traçando um paralelo (implícito) com a noção de formação discursiva, presente na obra de Michel Pêcheux. Isso porque as censuras impostas pelo mercado é que vão determinar aquilo que pode ser dito, a maneira pelo qual pode ser dito, e quem tem legitimidade para dizê-lo. Em outras palavras, "aquilo que numa posição dada, numa conjuntura dada (...) determina o que pode e deve ser dito (...)" (PÊCHEUX, 1988: 160). Isso fica ainda mais evidente nos capítulos nos quais Bourdieu desenvolve suas reflexões a partir das concepções de autoridade e instituição.

Numa análise sobre os ritos de passagem, que servem de marcadores entre aqueles que conseguiram ultrapassar a linha que os distingue dos outros (ainda não autorizados), ele irá afirmar que todo ato de instituição não passa de um ato inaugural de nomeação: "Instituir a alguém um nome, ou melhor, uma essência social" (BOURDIEU, 2008: 100). Tal ato só é possível a partir da inculcação das disposições duradouras, ou seja, daquilo que já está sempre aí, e que, por estar aí, se estabelece como um habitus naturalizador dos arbítrios culturais.

E mais, há um processo de objetivação pelo discurso. Essa objetivação se dá por um efeito do conhecimento (age-se sobre o mundo social agindo-se sobre o conhecimento dos agentes acerca do mundo) e não por uma determinação mecânica. Tal objetivação age por um tipo de classificação (distinção) que, por sua vez, ajusta-se às classificações objetivas e "acabam produzindo uma forma de conhecimento desta ordem que implica justamente o desconhecimento da arbitrariedade de seus fundamentos" (Idem, Ibidem: 117). Ao que parece, Bourdieu trata aqui da ideologia como um "tipo de adesão originária à ordem estabelecida", um "contrato tácito (...) que define a doxa originária" (Idem, Ibidem: 118).

Tal efeito - realizado a partir da objetivação pelo discurso - apresenta-se frequentemente em campos como o religioso, o político e o científico. A esse último, especialmente, Bourdieu exemplifica utilizando o que chamou de "efeito de teoria", ou seja, quando a vontade se torna realidade objetivada pelo discurso (e vice-versa). Um exemplo é a "aplicação" da teoria da classe e da luta de classes numa sociedade précapitalista por aqueles que, à luz da vontade de enxergar nesse passado uma "comprovação" da teoria marxista, acabaram por produzir um discurso (baseado num erro teórico) que objetiva a própria realidade 
por eles apontada.

É o que apresenta na análise do texto de Montesquieu, cuja obra buscou "comprovar", por meio de um aparato científico - ou um discurso cientificamente autorizado -, a teoria (ou mito) de que os povos do sul apresentariam características socioculturais inferiores às dos povos do norte em virtude da diferença climática. Mito que foi socialmente aceito principalmente por ter sido "enunciado em bloco" e de modo “cientificamente eufemizado", e que se perpetuou até o início do século XX (1).

Em tempo, a tese evocada por Bourdieu de que as palavras descrevem e prescrevem, de que têm capacidade de "produzir ou reforçar simbolicamente a tendência sistemática para privilegiar certos aspectos do real e ignorar outros" (BOURDIEU, 2008: 125), constitui-se como um importante instrumento teórico para aqueles interessados em investigar o poder simbólico constituído pelas palavras (a eficácia simbólica da linguagem na construção da realidade). Não as palavras em sua aparente neutralidade, mas as palavras dispostas em luta - na luta permanente pelo estabelecimento do consenso sobre o sentido, pelo estabelecimento de uma visão do mundo social.

\section{Bibliografia:}

BAKHTIN, Mikhail. Estética da criação verbal. São Paulo: Martins Fontes, 2003.

BOURDIEU, Pierre. A economia das trocas linguísticas. São Paulo: Edusp, 2008.

PÊCHEUX, Michel. Semântica e discurso: uma crítica à afirmação do óbvio. Campinas: Editora da Unicamp, 1988.

\section{Notas:}

(1) No Brasil, essa concepção esteve presente nas teses de "branqueamento" de Nina Rodrigues.

\section{Mini Currículo :}

Mestranda em Ciências da Comunicação do Programa de Pós-Graduação em Ciências da Comunicação da Escola de Comunicações e Artes (ECA-USP). Membro do MidiAto - Grupo de Estudos de Linguagem: Práticas Midiáticas. Bolsista Fapesp. 